\title{
Common Endodontic Treatment Challenge in an Elderly Patient: Negotiating Root Canal Impediments
}

\author{
Cendranata Wibawa Ongkowijoyo and Adioro Soetojo \\ Department of Conservative Dentistry, Faculty of Dental Medicine, Universitas Airlangga, Surabaya, Indonesia
}

\begin{abstract}
A male elderly patient came with buccal mucosa swelling associated with tooth 46 and 47 . Periapical radiograph confirmed the presence of periapical lesion and narrow root canals on both teeth. Challenging impediments were sensed upon negotiating most of the narrow root canals which were common in elderly patients. Glide path creation involved pre-flaring, K-file bending, watch winding movement, and very gentle strokes. After achieving patency, shaping, cleaning, and sealing phase can be performed.
\end{abstract}

Key Words: geriatric, elderly, endodontic, root canal impediments, negotiation, glide path

\section{INTRODUCTION}

The internal morphology of elderly teeth differs from young people. ${ }^{1}$ Due to masticatory forces, wear of teeth surface is inevitable. The wear of teeth surface, along with caries, and cavity preparation, will be followed by deposition of secondary and tertiary dentin in the pulp chamber. ${ }^{2}$ Oftentimes, root canals of elderly teeth also exhibit narrowing. ${ }^{3}$ Therefore, they present a significant challenge to the clinician when root canal treatment is indicated.

Impediments such as narrow root canal, internal irregularities, curvatures, and ledges might prevent apical advancement of root canal instrument; thus, there is some risk that apical patency and working length cannot be attained unless effective negotiation strategy is employed. ${ }^{4}$ Failure to negotiate the impediments will result in inadequate shaping, cleaning, and sealing of the root canal system. Hence, leaving apical portion of root canal infected and rendering root canal treatment prognosis to be questionable. ${ }^{5}$

\section{CASE REPORT}

A 65-year-old male patient came to the Conservative Dentistry and Endodontics Department Dental Hospital of Universitas Airlangga with complaint of gum swelling associated with right mandibular posterior teeth. The patient

Paper presented at the Joint Scientific Meeting in Special Care Dentistry, July 5, 2019, Amerta Room, 4th Floor, main campus of Universitas Airlangga, Surabaya, Indonesia.

Corresponding author: Adioro Soetojo Department of Conservative Dentistry Faculty of Dental Medicine Universitas Airlangga

Jl. Mayjen. Prof. Dr. Moestopo No. 47 Surabaya 60132 - Indonesia Email: adioro-s@fkg.unair.ac.id reported that those teeth suffered carious lesion many years ago and there was no pain associated with those teeth. Upon evaluation, the patient's medical history was found to be non-contributory to this case.

Extraoral examination showed healthy tissue around the posterior region of the right mandible. Upon clinical examination, buccal mucosa swelling associated with tooth numbers 46 and 47 was visualized. The buccal mucosa 
swelling was located around the height of the periapical region of both teeth and sinus tract was absent. Only tooth number 46 exhibited extensive carious lesions. Tooth 47 did not exhibit carious lesion. Thermal test with chlorethyl, bite test, and drilling both teeth did not yield any response. Therefore, both teeth were diagnosed as pulpal necrosis.

Radiograph examination allowed the detection of the carious lesions on distal surface of tooth number 47 . Root canals in both teeth could hardly be visualized giving the prediction of challenging impediments. There was also periapical radiolucency associated with the distal and mesial root of both teeth. The periapical radiolucency of the distal root of tooth number 46 was quite extensive that it reached furcal area (Figure 1).

After thorough examination, a treatment plan involving orthograde root canal treatment and direct resin composite restoration for both teeth was proposed and the patient agreed, and informed consent was signed.

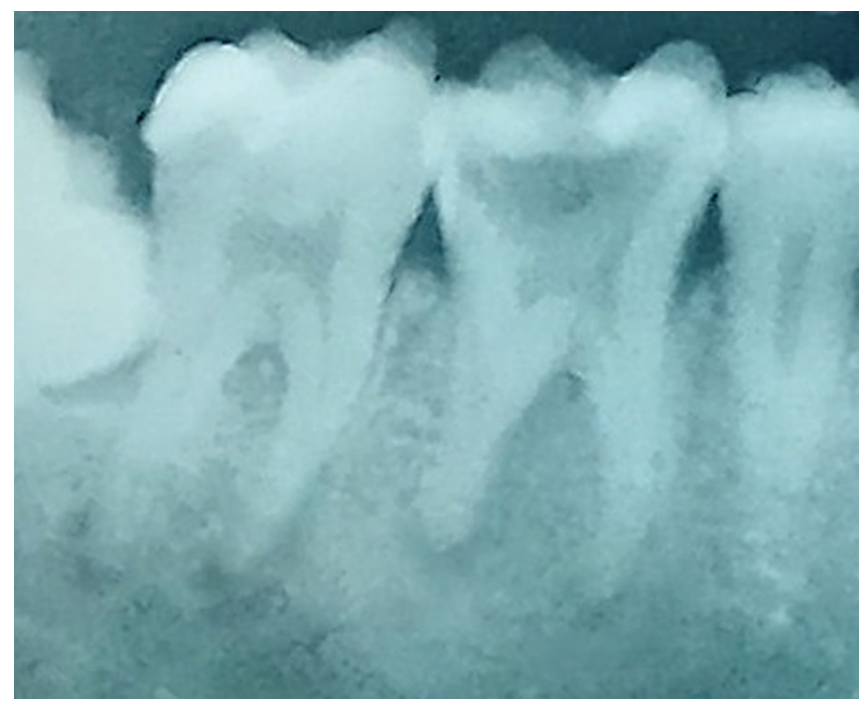

Figure 1. Pre-operative periapical radiograph showing narrow root canals with periapical lesion associated with tooth 46 and 47.

\section{Isolation and Access Opening}

Heavy rubber dam sheet, metal frame, and a non-metal clamp was used to isolate tooth number 46 and 47 . Carious lesion removal and access opening were performed with high-speed handpiece and round diamond bur. Surgical loupes with 6.0x magnification were used to aid visual inspection of orifices. Four orifices were found in tooth number 46 and three orifices were found in tooth number 47 (D MB ML).

\section{Negotiation}

Negotiation was performed with size 10 and $21 \mathrm{~mm}$ length D-Finder (Mani, Japan). ${ }^{6}$ Tight resistance and failure to advance apically were sensed upon negotiating all canals but distal root canal of tooth number 47 . Therefore, negotiation strategy for the impediments was needed to be prepared.

Rubber stop was set to measure the length of the impediment in each root canal. ProTaper Universal SX (Dentsply, USA) was used to enlarge the orifices for easier subsequent endodontic instrument insertion and to preflare the root canals up to $1 \mathrm{~mm}$ shy from the impediments to remove any coronal interferences. ${ }^{5,6,7}$

Root canals were flooded with EDTA (17\% EDTA solution). Size 10 and 21mm length D-Finder (Mani, Japan) was bent at $2 \mathrm{~mm}$ from its tip with tweezers up to $30^{\circ}$. The mark on rubber stop was aligned parallel to the direction of the file curvature. ${ }^{4,5}$ The bent D-Finder then was used to negotiate the root canals up to the level of impediment. At this time, the file should feel loose inside root canal after enlargement with ProTaper Universal SX (Dentsply, USA). Then, the file was rotated slightly (tip walking), and gentle 10-30 left-right rotation movement (watch winding) was employed along with slightly pushing the file apically, then withdrawn ${ }^{6}$ (Figure 2). If tight resistance was sensed, it means the file traversed the impediment, and the mark on rubber stop should be noted to memorize the direction to which the file tip advanced apically. ${ }^{4}$ Otherwise, the file should be rotated slightly again in different directions (tip walking). After few repetitions, the file should be removed and re-bent or replaced, and the root canal should be irrigated.
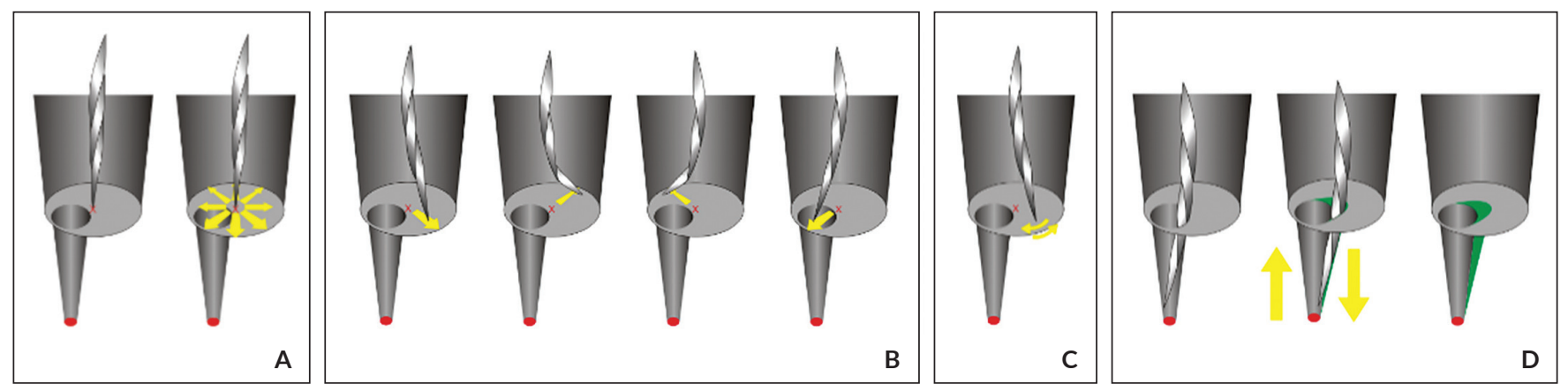

Figure 2. Illustration of hypothetical root canal impediment and its management. (A) Straight file cannot bypass the impediment; thus, it needs to be bend. 3D orientation of root canal space must be appreciated. (B) Tip walking movement is performed. (C) Watch winding movement. ${ }^{6}$ (D) Gentle push and pull motion. ${ }^{6}$ (Illustrations were drawn by author). 
After the apical advancement of the file, gentle pull and push motion should be employed at least 50 times to enlarge and smoothen the root canal dentin around the impediment, creating the glide path. ${ }^{4,5,6,7}$ Then, the file was removed for cleaning the flutes and for inspection of the impression of root canal curvature. After file removal, multiple curvatures on apical third of distolingual canal of tooth number 46 was observed. Subsequently, root canal was irrigated to flush out dentinal debris. The operator should be aware that there might be a presence of multiple impediments in different levels of root canal length.

\section{Working length measurement}

After achieving patency, working length was measured with an electronic apex locator (EAL) (Root Canal Meter YS-RZ-B, Yunsheng, China) and was confirmed with periapical radiograph. Periapical radiograph for working length confirmation showed a curvature on middle third of mesial canals of tooth number 47 (Figure 3).

\section{Shaping and Dressing}

Root canal shaping was performed with X-Smart Plus endo motor (Dentsply, USA), and endodontic rotary instruments consisted of Mtwo (VDW, Germany) and ProTaper Next (Dentsply, USA) (hybrid shaping).

The slender MTwo 10/04 and 15/05 (VDW, Germany) were used for the safety of initial root canal enlargement.

ProTaper Next X1 (D0=20, variable taper) and $\mathrm{X} 2$ ( $\mathrm{D} 0=25$, variable taper) (Dentsply, USA) then used subsequently for instrumentation and shaping of root canals until working length with single length approach. Shaping was done with a single stroke and clean technique to prevent the accumulation of debris in endodontic rotary instrument flutes, increase in instrument stress, and, extrusion of dentinal debris apically. ${ }^{8}$ The maximum torque setting

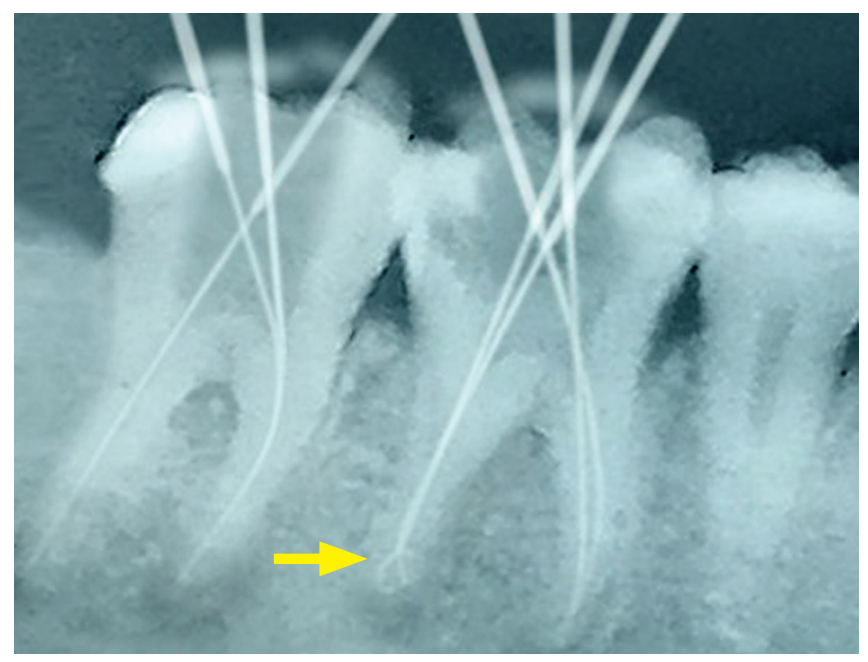

Figure 3. Working length confirmation with a periapical radiograph. Note the distal curvature in the distolingual canal of tooth number 46. was lowered than company instruction for more safety in instrumentation. Shaping phase was ended with ProTaper Next X2 until there was a presence of white, dentinal debris on the flutes of apical portion of the instrument, which means the apical portion of root canal dentine was adequately instrumented.

Calcium hydroxide paste (any-paste, Mediclus, Korea) was dispensed inside root canals as dressing material. Access opening of both teeth was temporarily sealed with temporary filling material (cavit, 3M ESPE, Germany).

\section{Cleaning and Sealing}

After two weeks, previously swollen buccal gingiva of the right posterior mandible has returned to normal contour, and both teeth were asymptomatic. Temporary filling material was removed. Calcium hydroxide dressing paste was removed from the root canals with sterile water irrigation and K-file.

For cleaning, side vented $30 \mathrm{G}$ irrigation needle (One Med, Indonesia) was used.17\% ethylene diamine tetraacetic acid (EDTA) was deposited inside root canals for one minute to dissolve inorganic debris. After that 17\% EDTA was flushed with sterile water. $2.5 \%$ sodium hypochloride $(\mathrm{NaOCl})$ was deposited inside root canals and activated for 30 seconds in each root canals with endoactivator (Dentsply, USA). $2.5 \% \mathrm{NaOCl}$ irrigation along with 30 seconds activation was repeated three times. Sterile water was used to flush out remaining $\mathrm{NaOCl}$ from the root canals.

Root canals were dried using endosuction and sterile paper points. Sealing of root canal system was performed with ProTaper Next X2 sized gutta-percha (Dentsply, USA) with AH26 (Dentsply, USA) sealer paste. The obturation technique employed was a single cone technique. (Figure 4) Ultrasonic scaler without water coolant can be used to cut the gutta-percha.

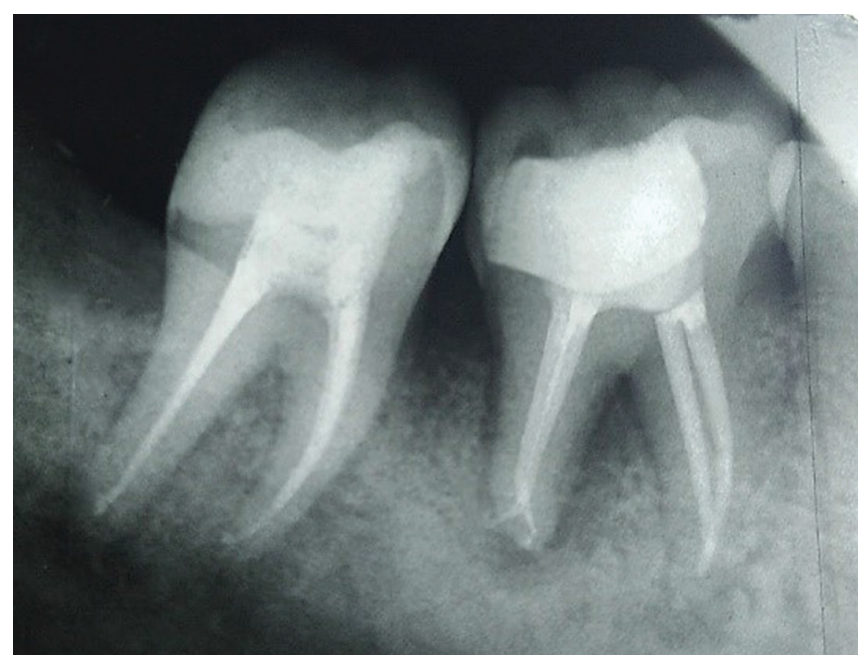

Figure 4. Tooth 46 and 47 after completion of root canal treatment and direct resin composite restoration. 


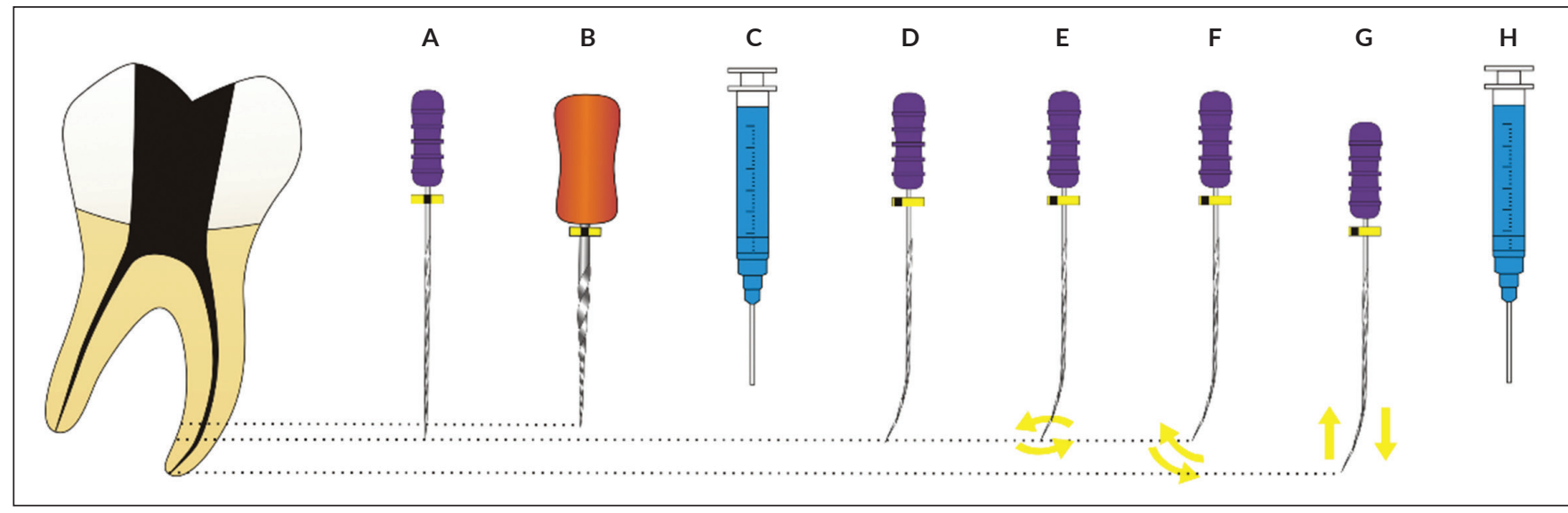

Figure 5. Sequence of root canal negotiation technique., ${ }^{4,5,6}(\mathrm{~A})$ Rubber stop is set to coronal reference point. (B) Coronal preflaring up to $1 \mathrm{~mm}$ shy from impediment..$^{5}$ (C) Irrigate. (D) High buckling resistance 10 sized file is bent and is inserted up to the level of impediment. ${ }^{4,5}$ (E) Tip walking movement. (F) watch winding movement. (G) gentle push and pull motion in $<1 \mathrm{~mm}$ amplitude is performed $>50 \mathrm{x} .{ }^{4}(\mathrm{H})$ Irrigate and file's flute is cleaned from debris. (Illustrations were drawn by author).

\section{Restoration}

Tooth number 46 and 47 were restored with direct resin composite Filtek Z350 XT (3M, Germany) to restore morphology, esthetic, and function of both teeth.

\section{Control}

After six months, both tooth numbers 46 and 47 were asymptomatic, the direct resin composite restoration was intact, and normal masticatory function was restored on both teeth.

\section{DISCUSSION}

In root canal treatment, each procedure highly affects the success of the subsequent treatment phase. The success of shaping, cleaning, and sealing cannot be predicted unless apical patency and glide path are achieved.5,4 Furthermore, the achievement of apical patency and the creation of glide path cannot be done unless effective negotiation strategy is performed, especially for challenging cases such as narrow root canal of elderly patients. ${ }^{5}$

It cannot be overstated that root canal negotiation is one of the most important phases in root canal treatment after access opening and locating root canal orifices. ${ }^{5}$ It requires appreciation of root canal dimension in $3 \mathrm{D}$, gentle movement, practice, time, and patience.

Preparation of instruments and materials for root canal negotiation includes: $17 \%$ EDTA to soften root canal dentin or $\mathrm{NaOCl}$ to dissolve remaining pulp tissue, endodontic instrument with narrow tip but high degree of taper for coronal preflaring and removing coronal interferences in root canal, and small endodontic file with high buckling resistance characteristic such as D-Finder (Mani, Japan) ${ }^{9}$ or C-Pilot (VDW, Germany). The rigidity of such endodontic file will allow itself to bypass root canal impediments. ${ }^{10}$

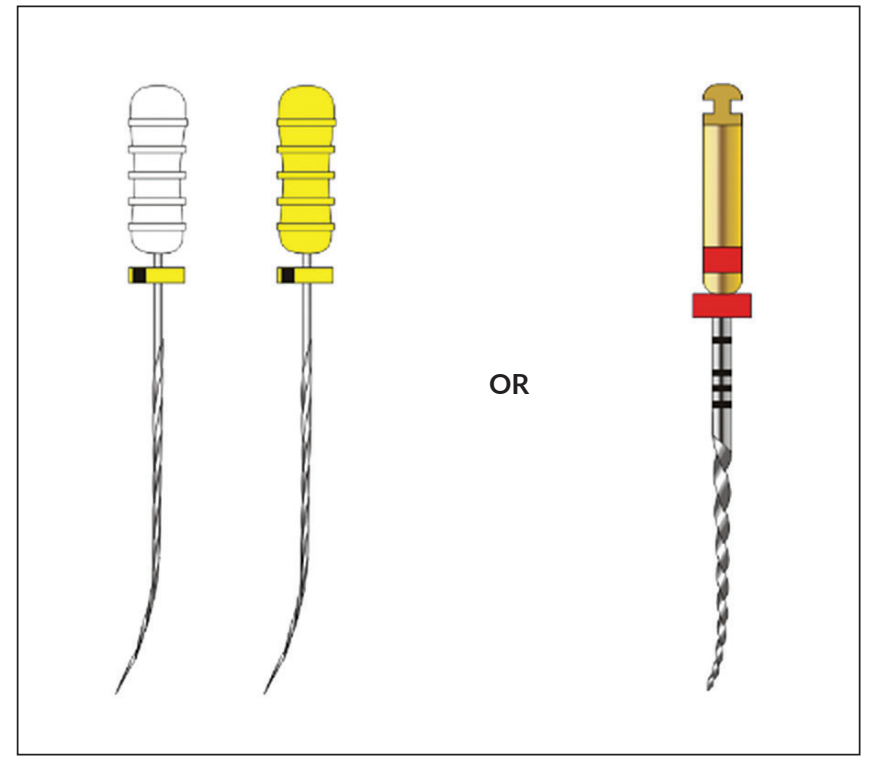

Figure 6. Further strategy to bypass impediments if shaping fails to reach terminus despite glide path establishment with sized 10 file. (Illustrations were drawn by author).

Figure 5 presents the negotiation strategy in a sequential manner.

Due to the severity of the impediment, sometimes the shaping instrument cannot bypass the impediment despite the established glide path. In this case, a bent 15 and 20 sized file should be used to enlarge the root canal prior to another shaping attempt., ${ }^{5,6}$ Alternately, the shaping file can be slightly bent, inserted by hand until bypassing the impediment, and then connected to the endomotor to start instrumentation (Figure 6). 


\section{CONCLUSION}

Glide path creation and apical patency achievement precedes effective shaping, cleaning, and sealing of root canal system. Root canal impediments pose a great challenge for clinicians in glide path creation; thus, an effective negotiation strategy is an invaluable skill to be learned and practiced to aid clinicians in bypassing impediments and creating glide path. ${ }^{5}$ Once root canal negotiation technique is effectively performed, this foundation for subsequent root canal treatment phase will allow shaping, cleaning, and sealing be performed successfully up to root canal terminus. ${ }^{5}$

\section{Statement of Authorship}

All authors participated in data collection and analysis, and approved the final version submitted.

\section{Author Disclosure}

All authors declared no conflict of interest.

\section{Funding Source}

None.

\section{REFERENCES}

1. Johnstone M, Parashos P. Endodontics and the ageing patient. Aust Dent J. 2015; 60 Suppl 1:20-7.

2. De Rossi SS,Slaughter YA. Oral changes in older patients: a clinician's guide. Quintessence Int. 2007; 38(9):773-80.

3. Singh SK, Kanaparthy A, Kanaparthy R, Pillai A, Sandhu G. Geriatric endodontic. J Orofac Res. 2013; 3(3):191-6.

4. Buchanan LS. Negotiating and shaping around anatomic root canal impediments. Roots. 2012; 24-30.

5. West J.The Endodontic Glidepath: 'Secret to Rotary Safety' [Internet]. Dentistry Today. 2010 [cited 2019 Mar]. Available from https://www. dentistrytoday.com/endodontics/3478-endodontic-glidepath-secretto-rotary-safety.

6. Cassim I, van der Vyver PJ. The importance of glide path preparation in endodontics : a consideration of instruments and literature. SADJ. 2013; 68(7):322-7.

7. Kaufman R, Serota KSS, Ruddle CJ. From concept to creation : a vision forty years on. Oral Health. 2006; 41-46.

8. Nasseh AA. Clinical Use of the ESX File System [Internet]. Inside Dentistry. 2014 [cited 2019 Mar]. Available from https://www. aegisdentalnetwork.com/id/2014/07/Clinical-Use-of-the-ESXFile-System.

9. Allen MJ, Glickman GN, Griggs JA. Comparative analysis of endodontic pathfinders. J Endod. 2007; 33(6):723-6.

10. Lopes HP, Elias CN, Mangelli M, Lopes WS, Amaral G, Souza LC, et al. Buckling resistance of pathfinding endodontic instruments. J Endod. 2012; 38(3):402-4. 